\title{
VALIDITY OF THE CULICID SUBFAMILY DEINOCERITINAE.
}

\author{
BY EVELYN GROESBEECK MITCHELL, WASHINGTON, D. C.
}

In the August number of Psyche is a very interesting paper on Deinocerites cancer, by Mr. Fredrick Knab. He seems, however, to be possessed of certain delusions, which I shall attempt to relieve.

Before proceeding to this, I wish to say that I was partly in error regarding the labial plate of this larva. I described the plate from a single dissected specimen. Mr. Knab has since then shown me the labial plate of another specimen. In this,and he says this is like others, - the two basal teeth and the central tooth are not, as I said (Psyche, Feb. 1906, p. 19, par. 4), longer than the rest, but are evenly graded; nor are the basal teeth spaced off any further than the rest. I believe that I described from a deformed specimen of the true labial plate and not, as Mr. Knab says, from an inner plate, but as the specimen is not now in my possession, I cannot absolutely verify this. I am aware that deformed labial plates are very rare; still I have seen a few. The teeth are otherwise as I described them, and I could tell the plate from any other at a glance, so characteristic is it.

I did not "bring forwàrd as a discovery of Mr. Coquillett" the unusual length of the second antennal joint in the adult. I merely quoted his statement to me as to the relative length of this joint in $D$. cancer as compared with the length in all other known forms of Culicidae.

Nor did I assert that only Deinocerites possesses a groove in which the mandibles move. It is not the presence of this groove but its prominent angulation which is characteristic of this larva. Mr. Knab himself admits that this is unusual when he says that though "the same lateral expansion of this region occurs again in the larva of the Sabethid Lesticocampa lunata, the modification of the ridge into rounded lobes, outward from the maxillae - occurs in most mosquito larvae but may be absent, as in Psorophora." (The italics are mine.) I have not seen a specimen of L. lunata and Mr. Knab's figure of it, (The larvae of Culicidae classified as independent organisms, by H. G. Dyar and F. Knab - reprinted from the Jour. N. Y. Ent. Soc., Vol. XIV, No. 4, Pl. XV. Authors separates pub. Mar. 14, 1906 - the paper itself having been published in December), does not show any lateral expansion much resembling that of Deinocerites, - which, by the way, has a much more prominent and sharp angulation of the groove than shown in Mr. Knab's ventral view of the head, (Pl. V, Psyche, Aug. '06). But even if L. lunata had such a groove as 
$D$. cancer, if only these two possess such an angulation surely this may be considered as one of the unusual if not unique characters of the latter larva.

As for the mandibles, I still believe these to be unique. I was careful, in view of possible discoveries, to say, ( PsYche, Feb. '06, p. 19, last par), in referring to the outer caudal angle of the mandible of other culicids than Deinocerites that "in other mandibles, so far as the writer can ascertain, this part forms an even, continuous curve with the rest of the mandible body." I had not then seen even the figure of $C$. vector. The straight, stiff, apparently spineless, (this is strange, as at least one or two rudimentary spines, though often hard to find, are present even on smoothly rounded mandibles), little projection on the outer angle of the mandible of $C$. vector is about as "similar" to the bent, thumblike, somewhat flexible, long-spined appendage on the $D$. cancer mandible as is the atrophied stump tail of a mandril to the prehensile caudal appendage of a South American monkey. Doubtless the projections are homologues. And, pray, on what are classifications based if not on modifications of homologous structures? Also, the outer angle of the mandible of $C$. vector is not, as in $D$. cancer, visible from above. The biting and other parts of the $C$. vector mandible are decidedly of the Culex type, as may be plainly seen by comparing them with my figure of a typical Culex mandible, (Psyche, Feb. '06, p. 11), and with the Deinocerites mandible illustrated on p. 17. (This figure, by the way, is, b! a misprint, wrongly designated as "Maxilla of C. salinarius," which is on p. 20). For the description of a variation of the marginal comb, which agrees with C. vector, read par. 2, col. I, p. 13, of the same number.

I have, from the first, regarded $D$. cancer as a primitive type, and it is natural that later developed types should possess atrophied remnants of organs which were well developed in the more primitive forms (such for example, as the spines on the outer caudal angle of the mandible). I find this belief supported by Osten Sacken, who states that he considers the true Nemocera, to which the Culicidae belong, and most of which possess numerous well developed sensory hairs on the antennae, as being a higher development than the Nemocera anomala, which have relatively bare antennae, (Ent. Mon. Mag., XXVII, p. 35). He lays great stress on the characters of eyes and antennae for forming superfamilies among the Diptera. As in the true Nemocera the differentiation of eyes is reduced to a minimum, he gives to the antennal characters, especially the comparative length and abundance of the hairs on the male as compared with the female antennae, the greatest importance. If, then, so great an authority considers antennal characters of this nature as of such moment in differentiating superfamilies, how much greater weight must be given to the value of the same characters in the making of subfamilies. 
Now in $D$. cancer the antennae of both sexes are unusually long and bear relatively short and few hairs; moreover the antennae of the male have neither longer nor more numerous hairs than those of the female. In all other Culicidae the antennae are comparatively short and with more and relatively longer hairs than in D. cancer; and except in the Trichoprosopininae, (which have other distinctive subfamily characters), the male antennae are densely plumose, with much longer and much more numerous hairs than in the female. Therefore according to Osten Sacken's theory, Deinocerites is the most primitive.

By the above antennal characters the Culicidae may be divided into three sharply marked primary groups as follows:

Antennae of males with much longer and more numerous hairs than those of the females. Antennae of females with long hairs. Second antennal joint in both sexes less than 8 times as long as wide. Metanotum nude. Outer caudal angle of mandible of larva not thumblike, or flexed, never with long spines or visible from above. Mandibular groove not angulated. Ventral brush present.

Contains the subfamilies Anophelinae, Megarhininae, Psorophorinae, Culicinae, Uranotaeninae.

Antennae of males not more plumose than those of females.

Antennae relatively short, the hairs of the antennae of both sexes well developed, second antennal joint less than 8 times as long as wide. Metanotum bristly. Mandible of larva as in above section. Mandibular groove sometimes angulated, (in L. lunata, according to Knab). Ventral brush absent.

\section{Subfamily Trichoprosoponinae.}

Antennae long in both sexes, the second joint over 14 times as long as wide, the antennal hairs in both sexes short and sparse. Metanotum nude. Outer caudal angle of the larval mandible visible from above, thumblike, flexed, somewhat movable and with many long spines. Mandibular groove forming a distinct angle below base of antennae. Ventral brush present.

\section{Subfamily Deinoceritinae.}

Thus it would seem that the conclusions at which I arrived by a study of the larvae are borne out by the important antennal characters in the adults and that the subfamily Deinoceritinae is at least as well marked as any other. 

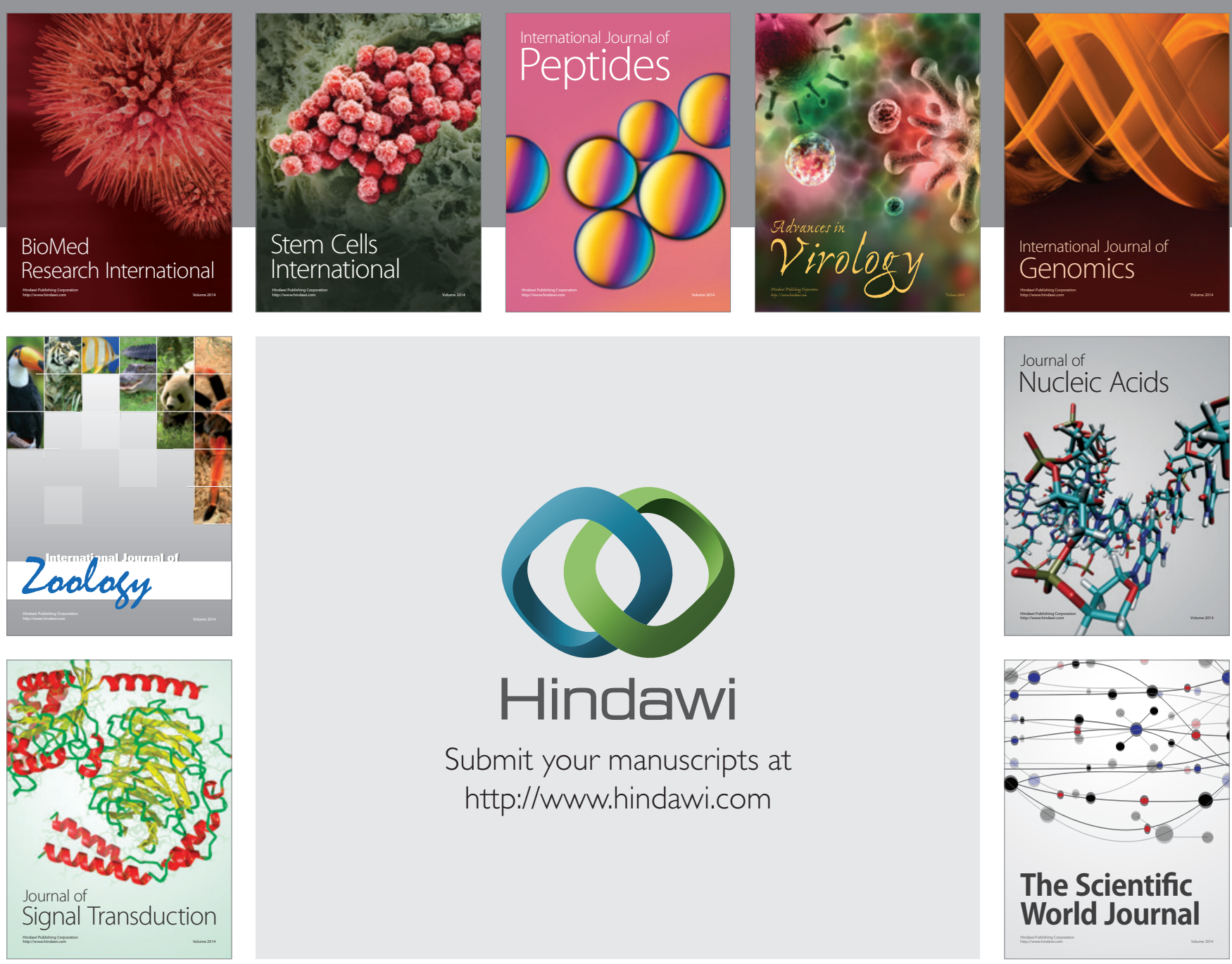

Submit your manuscripts at

http://www.hindawi.com
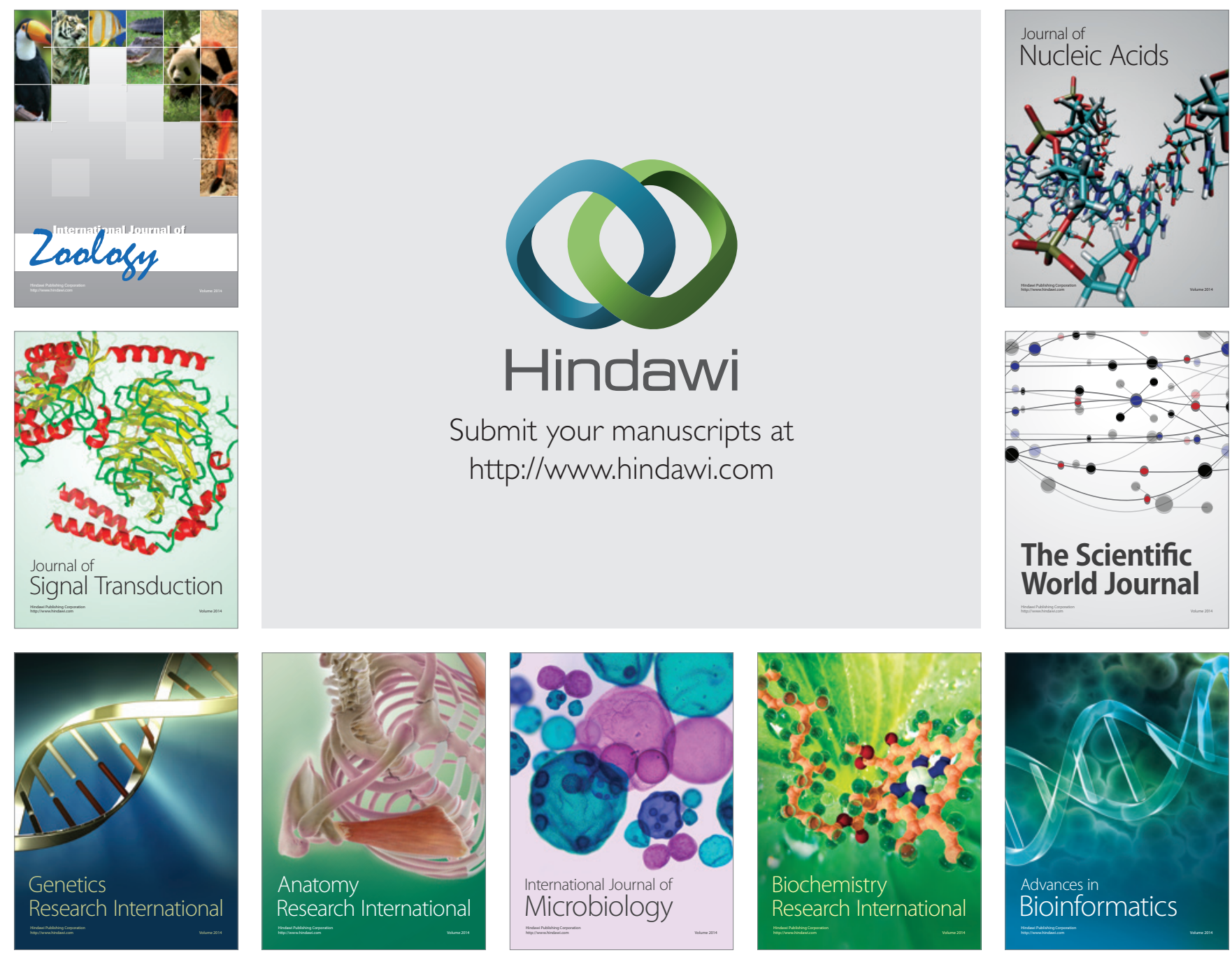

The Scientific World Journal
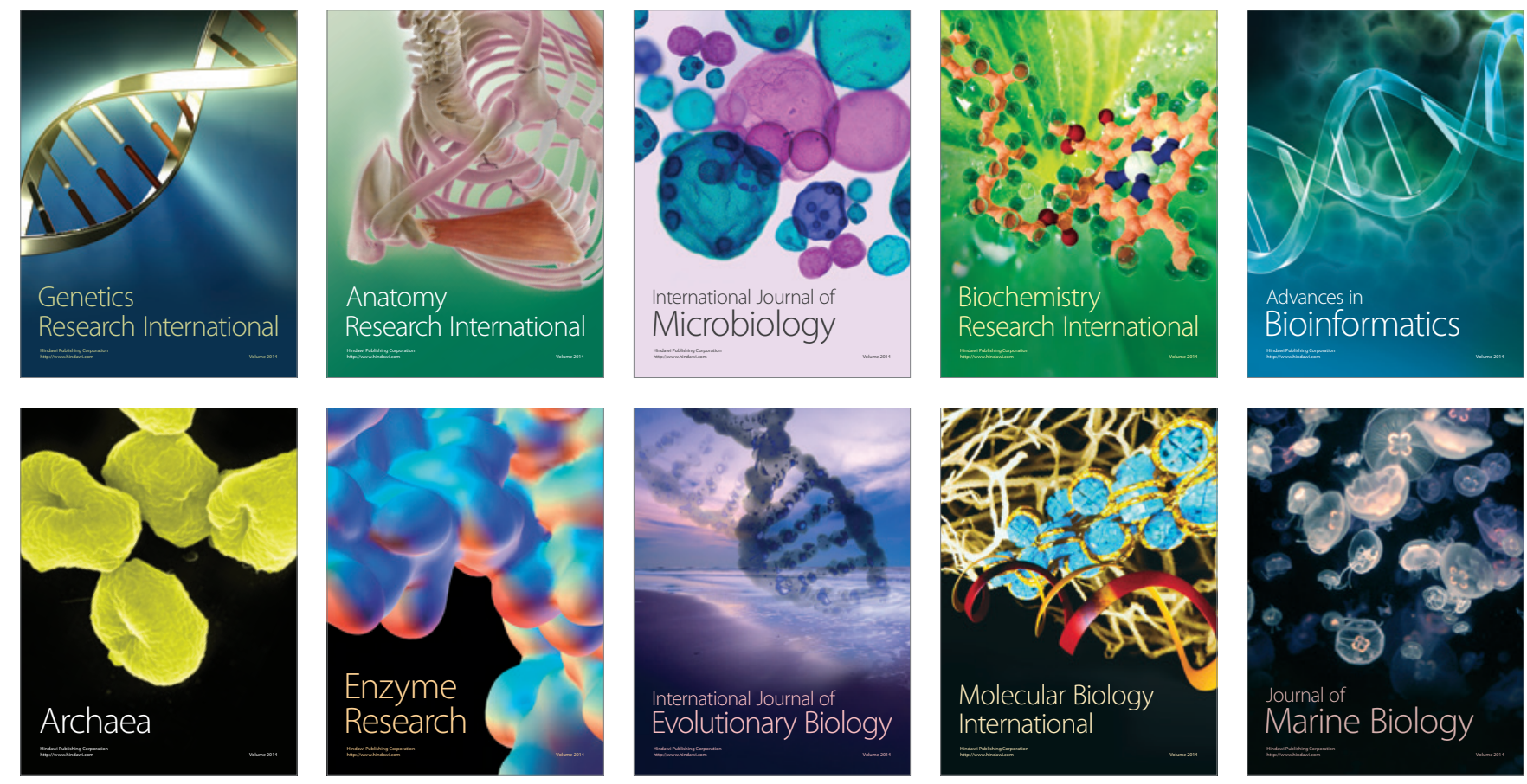